\title{
EFFECTS OF OWNERSHIP, SUBSIDIZATION AND TEACHING ACTIVITIES ON HOSPITAL COSTS IN SWITZERLAND
}

\author{
Mehdi Farsi $^{\dagger, \ddagger} \quad$ Massimo Filippini ${ }^{\dagger, \ddagger}$ \\ ${ }^{\dagger}$ Department of Management, Technology and Economics, \\ ETH Zurich, Zurichbergstr. 18, Zurich 8032, Switzerland \\ ${ }^{\ddagger}$ Department of Economics, University of Lugano, 6900 Lugano, Switzerland
}

April 2007

\begin{abstract}
\end{abstract}
This paper explores the cost structure of Swiss hospitals, focusing on differences due to teaching activities and those related to ownership and subsidization types. A stochastic total cost frontier with a Cobb-Douglas functional form has been estimated for a panel of 148 general hospitals over the six-year period from 1998 to 2003. Inpatient cases adjusted by DRG cost weights and ambulatory revenues are considered as two separate outputs. The adopted econometric specification allows for unobserved heterogeneity across hospitals. The results suggest that teaching activities are an important cost driving factor and hospitals that have a broader range of specialization are relatively more costly. The excess costs of university hospitals can be explained by more extensive teaching activities as well as the relative complexity of the offered medical treatments from a teaching point of view. However, even after controlling for such differences university hospitals have shown a relatively low costefficiency especially in the first two or three years of the sample period. The analysis does not provide any evidence of significant efficiency differences across ownership/subsidy categories. 


\section{Introduction}

The increasing growth of health care costs in Switzerland has raised the public interest in identifying the possibilities of improvement in productive efficiency. General hospitals (specialized clinics excluded) that account for about a quarter of national health expenditures have been subject of much debate but few studies. Farsi and Filippini (2006) and Steinmann and Zweifel (2003) have found significant differences in productivity and cost-efficiency among hospitals. Identifying the sources of such differences is an important policy issue that has not been explored sufficiently.

Ownership and subsidization as well as research and teaching activities have been considered as important cost-driving factors among Swiss hospitals. University hospitals have been often criticized for being excessively costly. Many policy-makers believe that public and subsidized hospitals are not as efficient as private facilities. However these policy debates remain qualitative and lack sufficient empirical evidence.

The present study addresses the above issues using data form a national sample of 148 general hospitals operating from 1998 to 2003. Compared to the previous research on Swiss hospitals this paper benefits from a larger data set and several additional variables especially those related to teaching activities. Moreover, the adopted methodology is based on some of the recent developments in stochastic frontier panel data models.

The analysis indicates that teaching activities can explain part of cost differences among hospitals. The results suggest that university hospitals while showing relatively high inefficiency, have improved over the sample period. There is no evidence of statistically significant efficiency differences among various 
ownership/subsidy types. The estimation results also point to unexploited economies of scale in a majority of the studied hospitals.

The rest of the paper is organized as follows. Section 2 provides a general description of the adopted methodology with discussions of the functional form and econometric models. Section 3 describes the model specification. The data and descriptive statistics are given in Section 4. The estimation results are presented and discussed in Section 5. Section 6 concludes the paper.

\section{Methodology}

Though many authors (Zuckerman et al., 1994; Linna, 1998; Rosko, 2001) have used cost frontier models to evaluate hospitals' efficiency, the application of such models in the health-care sector has been criticized (Newhouse, 1994; Skinner, 1994). The main arguments against these models are related to the unobserved heterogeneity due to differences in case-mix and quality of care as well as the errors incurred by aggregation of outputs. Horrace and Schmidt (1996), Jensen (2000) and Street (2003) have highlighted the sensitivity issues in the efficiency ranking of individual firms, which has been considered the frontier models’ main objective.

Virtually all frontier models rely on an assumption that the inefficiencies can be represented by certain asymmetric component of the stochastic error term. Such assumptions provide a convenient practical basis for separating the random noise from the inefficiency term. Moreover, they are often based on a sensible distribution assumption that assigns relatively high likelihood to full efficiency, thus providing a basis for comparison of individual firms with the bulk of the sample. However, it should be noted that these assumptions are in principle non-testable, and as pointed 
out by Street (2003), might create sensitivity problems for they link the identification of inefficiencies to the skewness of the residuals to a certain direction.

Admitting the difficulties involved in identifying the individual firm's relative efficiency, other studies (Folland and Hofler, 2001; Hadley and Zuckerman, 1994; Farsi et al., 2005) show the practical use of stochastic frontier analysis for comparing the performance across groups of providers. In addition, the new developments in stochastic frontier models for panel data proposed by Greene (2005) provide a better account of the hospital-specific unobserved heterogeneity. Following this thread of literature, we adopt a stochastic cost frontier approach to explore the efficiency differences across hospital types. The null hypothesis posits a similar distribution of inefficiency across different types, while the alternative suggests that hospital types differ in cost-efficiency perhaps due to various incentive mechanisms e.g. ownership/subsidy status, or differences in objective functions such as teaching and research purposes in university hospitals.

\section{Functional form}

Griffin et al. (1987) provide a comprehensive list of alternative functional forms and propose a series of criteria for model selection in cost and production analyses. The most important restrictions are related to the sample size and the estimation method. As the number of variables increase, most functional forms require a geometrically increasing number of parameters, thus necessitate much larger samples. The optimal choice is therefore a functional form that can be estimated with available estimation procedures and limits the number of parameters while using as many relevant variables as possible. One of the most commonly used functional forms is the CobbDouglas (log-linear) model (cf. Greene, 2004, 2003; Linna, 1998). Thanks to its 
limited number of variables this form has a practical advantage in estimation and interpretation, over more complicated forms. The main shortcoming of this model is the assumption of constant rate of scale economies which is considered as restrictive because by using the same proportional increase in output, small companies usually gain more than large firms.

The potential changes in scale elasticity with output can be analyzed using flexible functional forms such as translog. However, a translog model requires the estimation of a large number of parameters. Furthermore, the included second-order terms could cause multicollinearity, which can affect the model's statistical performance. Especially with the multiple error component model used in this study and the available sample size, such problems could induce numerical problems resulting in degenerate stochastic terms. In fact, our preliminary analyses showed that a numerically feasible estimation of a translog cost frontier with non-degenerate stochastic components was only possible with simplified specifications that excluded several important output characteristics.

Using a parsimonious translog model with a homothetic cost function and its corresponding Cobb-Douglas model, we performed an exploratory analysis to identify the effect of functional form on the results. The results indicate that: first, the main estimated coefficients do not change much across the two functional forms. Particularly, the main output coefficients used for estimating the scale economies are quite similar to those of the complete model used here. Secondly, the efficiency estimates obtained from the translog model are highly correlated (higher than 90\%) with those of the corresponding parsimonious Cobb-Douglas model. The main differences in efficiency estimates appeared when we included the deleted variables and more importantly with a change in econometric specification. These results 
suggest that in our case the choice of explanatory variables and the econometric specification of unobserved heterogeneity have a greater importance than the functional form. We therefore decided to focus on the Cobb-Douglas form that allows a larger number of explanatory variables.

Resulting from a minimization problem given input prices and outputs, cost functions must be non-decreasing in outputs and concave and linearly homogeneous in input prices (Cornes, 1992). In particular, the latter condition is usually imposed by dividing the input prices by a numeraire price, thus ensuring the input shares add up to 1. In this paper, this condition is not imposed mainly because as we will see later, the available data does not allow a complete account of all input factors.

\section{Econometric models}

There are a number of econometric approaches to estimate stochastic cost frontier models (Kumbhakar and Lovell, 2000). The original cost frontier model (Aigner et al., 1977) applied to panel data can be written as:

$$
\ln T C_{i t}=f\left(Y_{1 i t}, \ldots, Y_{M i t} ; P_{1 i t}, \ldots, P_{N i t} ; Z_{1 i t}, \ldots, Z_{K i t}\right)+u_{i t}+v_{i t}
$$

where subscripts $i$ and $t$ represent the firm and year respectively; TC is the total costs; $Y_{m}(m=1, \ldots, M)$ are the outputs; $P_{n}(n=1, \ldots, N)$ are the input factor prices; $Z_{k}(k=1$, $\ldots, K)$ are output characteristics and other exogenous factors that may affect costs; $v_{i t}$ is the random noise or unobserved heterogeneity; and $u_{i t}$ is a positive stochastic term representing inefficiency, typically with a normal-half-normal distribution: $u_{i t} \sim\left|N\left(0, \sigma_{u}^{2}\right)\right|, \quad v_{i t} \sim N\left(0, \sigma_{v}^{2}\right)$. The firm's inefficiency is estimated using the 
conditional mean of the inefficiency term as proposed by Jondrow et al. (1982), that is: $\mathrm{E}\left[u_{i t} \mid \hat{\varepsilon}_{i t}\right]$, where $\varepsilon_{i t}=u_{i t}+v_{i t}$.

Assuming a time-invariant inefficiency term $u_{i t}=u_{i}$, this term can be identified by panels' individual fixed or random effects. The resulting specifications (Pitt and Lee, 1981; Schmidt and Sickles, 1984) relax the distribution assumptions on stochastic terms, in particular in the fixed effect specification the individual firm effects $\left(u_{i}\right)$ do not need to be uncorrelated with explanatory variables. Several authors (Battese and Coelli, 1992; Cornwell et al., 1990: Sickles, 2005) have extended the above panel data models to include time-variant inefficiency. Others (Greene, 2004, 2005; Kumbhakar and Hjalmarsson, 1995; Kumbhakar; 1991; Polachek and Yoon, 1996) have adopted another approach in which a stochastic firm-specific term (fixed or random effect) is added into the original stochastic frontier model presented in Equation (1). This approach allows a distinction of unobserved time-invariant heterogeneity across firms, which is particularly important in hospitals characterized by strong unobserved heterogeneity associated with case mix and quality differences.

In particular the random intercept frontier model ('true' random effects frontier model) proposed by Greene $(2004,2005)$ has been successfully used in other sectors (Farsi et al., 2005). This model can be obtained by adding a firm-specific stochastic term $\alpha_{\mathrm{i}} \sim N\left(0, \sigma_{\alpha}^{2}\right)$, on the right-hand-side of Equation (1). As opposed to alternatives with fixed effects, this model does not have the incidental parameters problem. The main difficulty of this model is in its numerically cumbersome estimation method. As the likelihood function does not have a closed from, this model is estimated using Simulated Maximum Likelihood (SML) method, in which $\alpha_{\mathrm{i}}$ 's are simulated by random draws. Because of non-linearity of errors in the number of 
simulations, the SML estimators require a large number of simulations or might show sensitivity to the draws (Gouriéroux and Monfort, 1996).

In this paper, we use the Greene’s true random effect frontier model, labeled here as TRE. We use pseudo-random Halton draws to minimize the potential sensitivity of the results to simulations. Number of draws has been fixed to 1000. Our sensitivity analysis using several options suggested that the estimations are not sensitive when the number of draws is higher than a few hundred. The inefficiency is estimated using the (simulated) conditional mean of the inefficiency term $\left(u_{i t}\right)$ given by $\mathrm{E}\left[u_{i t} \mid \hat{\omega}_{i t}\right]$, where $\omega_{i t}=\alpha_{i}+u_{i t}+v_{i t}$. In addition to the TRE model, we estimated the original pooled frontier model as shown in Equation (1). The contrasting difference between the two models is that unlike the pooled model, in the TRE specification, the persistent cost differences are excluded from inefficiency estimates. In this sense the two models can be used to provide complementary estimates of persistent and transient inefficiencies.

\section{Differences across ownership/subsidization types}

Although, economic theory predicts lower costs for organizations with relatively high-powered financial incentives such as for-profit and non-subsidized firms, the empirical evidence is rather mixed. While some studies (Eakin, 1991; Steinmann and Zweifel, 2003) conclude no significant differences, a few others (Li and Rosenman, 2001; Carey, 1997) report slightly lower costs in for-profit hospitals compared to non-profit ones. In this paper, the effects of ownership/subsidization status on efficiency are studied using a two-stage method. This method is based on testing the significance of differences across hospital groups. We use the Kruskal- 
Wallis (1952) rank test (KW) as well as the t-test with unequal variances. The KW test is a non-parametric test that has been often used in frontier analysis (Singh and Coelli, 2001). Given that the hospital types are more or less constant over the sample period (no change in subsidy status and only 9 cases of ownership change), the tests have also been performed on the hospital average values over the sample period but have not shown much difference in the outcome.

The two-stage approach has a disadvantage in that the first-stage estimation errors may affect the results of the test in the second-stage. These errors may lead to an under-rejection of the null hypothesis postulating similar cost-efficiencies across different categories (Farsi and Filippini, 2004). On the other hand, the two-stage approach allows the use of non-parametric statistical tests based on efficiency ranks rather than efficiency values that are subject to relatively large estimation errors and sensitive to outliers. An alternative approach is to include type indicators in the regressions and test the significance of the corresponding coefficients. We performed a GLS estimation of this alternative specification to confirm the results of the twostage procedures. Our data show that the subsidization status has not changed over the sample period and only 9 hospitals have changed ownership status from one year to another.

\section{Model specification}

The specification used in this study is based on two main outputs: hospitalizations and ambulatory care. In line with Linna (1998), Rosko (2001) and Heshmati (2002) the main measure of hospitalization output is taken as a DRG weighted number of hospitalizations (denoted by $Y$ ). This approach was prefered over the alternative based on multiple output categories based on DRG weights (Brown, 
2003), mainly because such categories might be arbitrary as the DRG weights define the cost intensity of the cases rather than different outputs.

Since the number of outpatient cases is not available in the data, the ambulatory output is approximated by the corresponding revenues adjusted for inflation $(A M B)$. This approximation is based on the assumption that the average unit price of ambulatory care is similar across hospitals. Three input factors are considered: capital, physicians' input and all other employees' labor. Similar to Wagstaff and Lopez (1995) and Rosko (2001), capital prices (PK), are approximated by the hospital's total capital expenditure divided by the number of available beds in the hospital.

Labor prices $\left(P L_{1}\right.$ and $\left.P L_{2}\right)$ are calculated by dividing total salaries by the number of remunerated days. In line with Folland and Hofler (2001) and Scuffham et al. (1996) among others, physicians and non-physicians are considered as two separate labor inputs. The physicians' labor price represents the average salary of those employed by the hospital and exclude honoraries and fees, accounting on average for about $5 \%$ of the hospital's total costs, usually paid to both employed and unemployed physicians. Both labor prices are proportionally adjusted for social benefits, accounting on average, for about $9 \%$ of total costs. These charges are proportionally distributed to physician and non-physician groups, the proportions being the respective shares of each group's salaries. This adjustment captures the potential variation in social benefits across hospitals due to differences in pension funds as well as the age and seniority of the employees mix.

The three input factor prices considered in the model correspond to about 70 percent of a hospital's total cost on average. The available data do not allow an appropriate calculation of the prices of remaining inputs such as medical materials, 
food, water and power as well as physicians' fees and other personnel charges. The excluded prices are obviously not constant and neglecting their variation could affect the estimation results. However, some of these variations are probably captured by the three included factor prices. For instance, physicians’ fees are likely to be correlated with physicians' salaries. Another concern is the accuracy of the price data that may create bias in the price coefficients. However, other coefficients will not be affected if these measurement errors and the unobserved factor prices are uncorrelated with explanatory variables.

Similar to Vita (1990), Scuffham et al. (1996) and Carey (1997) the average length of hospitalization (LOS) has been included in the model. In addition to representing hospital’s ‘hotel services’ like nursing care and accommodation (Breyer, 1987), this variable provides a measure of severity of the case mix within each DRG. In fact, there is a considerable variation among patients within a DRG, as indicated by the wide range of acceptable hospital stays provided by the Swiss DRG Association (APDRG Suisse, 2003). The number of hospital departments (medical units $M U$ ) is also included to represent the range of specializations offered in the hospitals. Each one of these centers provides a single specialization. Hospitals with a wider variety of medical specializations are expected to be more costly than those with similar output but from fewer specializations. Another cost-driver is the number of non-medical units (TU) including medico-technical, therapeutic and infrastructure units. The operation costs of these units are also included in the observed total costs.

The share of outpatient clinics over total medical units (AMBC) operated by the hospital is also included as a complementary measure of ambulatory output in the model. The level of hospital's teaching activities is measured by the total number of internship positions (NP) offered in the hospital. The internships might have different 
levels of complexity and specialization. In order to account for such differences we used the Swiss Medical Association’s classification that applies to internship positions and hospital departments. We included the percentage of the internship positions recognized as the two top categories $(A B)$ and that of the hospital's departments accredited for specialized medical training $(F M H)$. These two variables are expected to represent the complexity level of the hospital's medical care.

Hospitals' costs can also be affected by the quality of care. The evidence on the effect of quality measures on hospital costs is not conclusive. Zuckermann et al (1994), Rosko (2001) and Vitaliano and Toren (1996) conclude that quality indicators do not have significant cost effects, whereas others such as Folland and Hofler (2001) suggest a significant effect for structural quality measures such as bed availability and the share of board-certified physicians. This may be explained by the fact that unlike outcome or process measures the structural quality is usually easier to observe and has a more directly measurable effect on costs. As we do not have access to patient-level data or any reliable outcome measure quality from Swiss hospitals, in this paper we focus on structural measures of quality. In addition to the share of accredited medical units and training positions, we included the hospital's nurse per bed ratio $(N B)$ to represent the quality of nursing care.

We also included two binary indicators for emergency room $(E R)$ and geriatrics department (GER). While emergency services are usually involved with relatively severe cases, geriatrics cases are less intensive in medical care thus less costly. Year dummies (Y99 through Y03) are included to capture the overall technological progress and the potential temporal variations in unobserved variables such as reporting procedures.

The specification of the true random effects model can therefore be written as: 


$$
\begin{aligned}
\ln T C_{i t}= & \beta_{0}+\beta_{1} \ln Y_{i t}+\beta_{2} \ln A M B_{i t}+\gamma_{1} \ln P K_{i t}+\gamma_{2} \ln P L_{1 i t}+\gamma_{3} \ln P L_{2 i t} \\
& +\omega_{1} \ln L O S_{i t}+\omega_{2} \ln N B_{i t}+\omega_{3} \ln M U_{i t}+\omega_{4} \ln T U_{i t}+\omega_{5} \ln N P_{i t} \\
& +\rho_{1} A M B C_{i t}+\rho_{2} F M H_{i t}+\rho_{3} A B_{i t}+\delta_{1} E R_{i t}+\delta_{2} G E R_{i t} \\
& +\delta_{99} Y 99_{t}+\delta_{00} Y 00_{t}+\delta_{01} Y 01_{t}+\delta_{02} Y 02_{t}+\delta_{03} Y 03_{t}+\alpha_{i}+u_{i t}+v_{i t}
\end{aligned}
$$

The stochastic components $\alpha_{i}, u_{i t}$ and $v_{i t}$ respectively represent the hospital-specific random effect, inefficiency term and random noise with a normal-half-normal distribution. The pooled model is a special case, in which the stochastic component $\alpha_{i}$ is set equal to zero.

The above specification leaves out several important factors. Namely the available data do not provide any measure of severity variation for outpatients and those within each DRG or a better measure of hospital's ambulatory output especially the ER visits. More importantly, the model lacks an outcome measure of less observable quality differences across hospitals. Assuming that these unobserved factors are independent of the included explanatory variables, their omission does not bias the results. However, this might be a restrictive assumption as in many cases, the correlation between those differences and hospital size or type is rather plausible. For instance, assuming a positive relation between costs and quality, higher unobservable quality for non-profit hospitals would imply an overestimation of their inefficiency compared to other hospital types. The results of this paper should therefore be considered within the limits of the available data and the related simplifying assumptions.

\section{Data}

The data used in this paper are extracted from the annual financial and administrative data reported by general hospitals to the Federal Statistical Office (SFSO, 1997a) from 1998 to 2003. These data have been merged with another data set 
consisting of an aggregate extraction of the medical data of the Swiss hospitals with records for individual hospitalizations (SFSO, 1997b). The extracted medical data consist of the number of cases by AP-DRG in each hospital-year, including about a million observations. Using the cost weights from Swiss AP-DRG version 4.0 (APDRG Suisse, 2003), we calculated an average cost weight for each hospital-year. The adjusted number of admissions is then calculated by multiplying these average cost weights by the number of admissions recorded in the administrative data.

After excluding the observations with missing and invalid values from an unbalanced panel with 1082 observations from 221 general hospitals, the final sample was created with 623 observations from 148 hospitals operating from 1998 through 2003. The excluded observations are mainly those with missing DRG data or erroneous values for outpatient revenues. We also excluded three hospitals with fewer than 20 beds. In general, the excluded observations with missing or suspicious values include higher proportion of small-size hospitals. T-tests suggest that the excluded observations are from hospitals with significantly lower number of beds (an average of 110 beds). However, similar tests indicate that there is no significant difference in average cost per hospitalization across the two groups. A descriptive summary of the sample listed in Table 1, shows a considerable variation among hospitals in most variables. Particularly while the average cost of a hospitalization varies from 4,500 to 54,000 Francs, the average DRG cost weight ranges from .52 to 1.47 and an average hospitalization lasts from 4 to about 50 days.

\section{Insert Table 1}

The sample also includes all the five university hospitals in Switzerland. These hospitals stand out from the rest of the sample in several ways. With an average size of 1030 beds, DRG cost weight of 1.07 , LOS of 8.3 days and an average cost of 
19,700 Francs per hospitalization these hospitals are on average larger and treat a relatively severe patient mix with relatively short but expensive hospitalizations. These statistically significant differences (shown by t-test) might suggest the possibility of a different technology, hence a different cost function in university hospitals. However our preliminary regressions on a sample excluding the university hospitals indicate that the results do not change significantly, suggesting that these hospitals can be pooled with the rest of the sample. Moreover, the correlation between the efficiency estimates within each econometric model is higher than $98 \%$ between the samples with and without university hospitals.

The number of general hospitals in the sample and their average capacity by ownership/subsidy types are listed in Table 2. All public hospitals and most private non-profit hospitals are subsidized, whereas in the private for-profit sector, a large fraction of hospitals are not. Table 2 also lists the average hospital size measured by the number of beds for each ownership/subsidy type. Public hospitals with an average of 262 beds are by far the largest providers of health care in the sample. Subsidized hospitals are also considerably larger than non-subsidized ones.

\section{Insert Table 2}

\section{Results}

Table 3 lists the regression results of the cost frontier analysis as in Equation (2). The estimated coefficients are mostly significant and generally have the expected signs. Overall, the differences across the two models, while being statistically significant in many cases, are not considerable for practical purposes. The results especially those of the TRE model are also comparable to a similar model estimated by GLS given in the appendix (Table A.1). According to the TRE model a ceteris 
paribus increase in the adjusted number of hospitalization by $1 \%$ will result in about $0.7 \%$ increase in total costs. As expected, the effect of ambulatory output is much smaller, suggesting a marginal cost of about five times.

\section{Insert Table 3}

The regression results indicate that LOS is an important predictor of hospital costs. Given that hospital stays are on average about 10 days, this implies that a difference of one day in the hospital's average LOS is approximately equivalent to $4 \%$ of total costs. This could be considered as an important policy implication in the context of Switzerland, where local hospitals have been criticized for their excessively long hospitalizations. However, the apparently considerable savings by curtailing hospital stays should be considered with caution. First, the costs of medical treatment are not evenly distributed over the course of a hospitalization and the final days are usually less costly. Secondly, as confirmed by the smaller effect in the TRE model that has a better control for unobserved heterogeneity, LOS variable also captures part of the unobserved differences in case mix severity that are beyond the hospital management's control.

As expected, the price coefficients are positive and significant. However, these estimates significantly differ from the average actual share of the corresponding input factors (about 7, 11 and 53 percent for capital, physician services and other employees). This result can be related to the fact that because of labor contracts and other institutional and practical restrictions hospitals are not fully responsive to changes in input prices. This might imply that hospitals do not completely minimize their total costs. It should also be noted that hospitals might have other objectives in addition to cost minimization, in which case functions based on cost optimization can still be used as a "behavioral" cost functions and can be helpful in studying the firms' 
behavior rather than their production technological characteristics (Breyer, 1987; Bös, 1986).

As seen in Table 3, the number of hospital units has a significant effect on total costs, suggesting that hospitals with a wider range of specialization and also those with more non-medical services are relatively more costly. However the estimated coefficients suggest that such cost differences are relatively small. The marginal cost of internship positions is also low but statistically significant. The results predict an average increase of $0.9 \%$ in total costs for $10 \%$ increase in the number of positions. The teaching quality regarding medical specialization has also a statistically significant effect on hospital costs, but the marginal effects remain quite low.

The share of ambulatory clinics has a negative and significant effect, consistent with the fact that ambulatory visits are usually less costly than inpatient care. The TRE model suggests that for instance, an increase of 10 percentage points in the share of ambulatory clinics thus 10 points decrease in the share of inpatient units, results in a decrease of about 3\% in the hospital's total costs. The nurse per bed ratio has a relatively high and significant effect, indicating that the cost of nursing care is quite considerable. As expected, the ER dummy has a positive coefficient and the geriatrics dummy has a negative effect. The coefficients of the year dummies suggest a positive growth in hospital costs starting from 2000, with an average annual rate of 1 to 3 percent.

Regarding scale economies, the results listed in Table 3 indicate that the returns to scale (inverse of the main output elasticity) are on average significantly higher than 1 (1.4 or 1.6 depending on the model). This suggests that the majority of general hospitals in Switzerland do not fully exploit the potential scale economies. 
However, it should be noted that these economies are likely to be marginal for large hospitals with more than 130 to 200 beds (Vita, 1990; Crivelli et al., 2001; Aletras, 1999; Dranove, 1998).

\section{Overall cost-efficiency}

Table 4 provides a descriptive summary of the inefficiency scores estimated by the two models. The inefficiency scores obtained from the two models are significantly correlated with a correlation coefficient of 0.56 and a Spearman rank correlation of .53. According to the pooled model, the inefficiency is less than 8 percent for half of the sample but a quarter of the studied hospitals show $11 \%$ or more excess costs. As expected, the pooled model's estimates are generally higher than those of the TRE model that separates part of the hospital-specific heterogeneity. The latter model suggests that on average, about 6 percent of the hospital costs cannot be explained by the included explanatory variables or by a symmetric stochastic term.

Noting that the "true" inefficiencies cannot be exactly identified, the estimated inefficiencies can be interpreted as the excess costs compared to the best observed practice provided that the omitted variables are captured by symmetric stochastic components. While we cannot favor one model over the other, we assert that given the important unobserved factors related to quality and case-mix severity the TRE model is likely to give a better picture of excess costs. On the other hand in the context of Swiss hospitals, because of strong regulation and institutional restrictions managers might be unable to adapt with changing conditions thus persistent inefficiencies might be relatively important. In this case the TRE model might understate the sector's overall inefficiency. 


\section{Insert Table 4}

These inefficiency estimates are in general lower than those reported in previous studies for the Swiss hospitals (Farsi and Filippini, 2006; Steinmann and Zweifel, 2003; Steinmann et al., 2004). However, the differences can be explained by several additional characteristics included in this paper, such as teaching and specialization variables as well as a different methodology in separating heterogeneity from inefficiency differences. The results are comparable to similar estimates reported in the literature for the US hospitals, ranging from 5 to 15 percent (Zuckerman et al., 1994; Folland and Hofler, 2001; Eakin, 1991), but differ from other studies particularly those on European samples, which estimate generally higher levels of inefficiency amounting to 20 to 30 percent (Linna, 1998; Wagstaff, 1989; Wagstaff and Lopez, 1995; Steinmann et al., 2004; Bruning and Register, 1989). It should be noted that even the seemingly low values estimated from the TRE model are equivalent to considerable excess costs amounting, for instance in 2003, to about 590 million Francs out of the actual total costs of 10.7 billion Francs for the hospitals in the sample. The 6 percent average inefficiency is also equivalent to 2 or 3 years efficiency lag according to the efficiency targets set by the UK health care authorities (Jacobs and Dawson, 2003).

\section{Cost-efficiency in university hospitals}

The estimation results suggest that university hospitals are on average less efficient than other hospitals. However, this difference is not statistically significant in the TRE model. Excepting the university hospitals the average efficiency estimates do not show any significant changes over time. University hospitals however show a 
different pattern with a relatively high inefficiency in the first years (1998 to 2000) and a decreasing trend over the sample period (Figure 1).

\section{Insert Figure 1}

Several t-tests on the university hospitals' efficiency scores across different years suggest that the efficiency improvement in university hospitals is statistically significant. According to these estimates, from 1998 to 2003, university hospitals have considerably reduced their excessive costs. Part of these changes could be explained by the variation of case mix severity. In fact, the trends in AP-DRG cost weights suggest that the severity of the patient mix has grown relatively more in university hospitals (Figure 2). Over the sample period the average cost weight for university hospitals has increased from 0.99 to 1.17 whereas the corresponding change in other hospitals is from 0.78 to 0.84 . Given that in Switzerland, DRG coding has been introduced in 1998, some of such increases might be related to changes in the quality of DRG coding especially in university hospitals that, having relatively severe cases, require a more elaborate coding practice. In this case the observed changes in efficiency of university hospitals could be an artifact of a different DRG coding.

\section{Insert Figure 2}

In order to explore the relationship between changes in severity and inefficiency, we estimated another model similar to Equation (2), with the only difference that the number of admissions is not adjusted for AP-DRG cost weights. The inefficiency estimates of this analysis still show a slight but still statistically significant improvement in university hospitals over the sample period. These results indicate that part of efficiency gains in university hospitals could be related to the fact 
that these hospitals increasingly treat more severe cases. However, even if we assume that the observed severity trends are entirely related to gradual effect of better coding practices, the results still indicate that on average university hospitals have improved.

\section{Effects of ownership/subsidy types}

The average inefficiency estimates are listed by ownership and subsidization categories in Table 5 and Table 6 respectively for the pooled and TRE models. These results point to some differences among various hospital types. We explored the significance of these differences with several Kruskal-Wallis and t-tests. Several possible groupings have been considered. In summary, the TRE model's inefficiency estimates do not show any statistically significant difference across hospital types. The estimates obtained from the pooled model are significant at $10 \%$ level only for a single case, suggesting a higher efficiency in subsidized versus non-subsidized hospitals. Overall, consistent with the results reported in previous studies (Farsi and Filippini, 2006; Steinmann and Zweifel, 2003), this analysis suggests that after controlling for other factors, subsidization and ownership do not have any significant effect on hospital costs. This is also confirmed by the GLS model in which the three type indicators remain statistically insignificant (Table A.1).

\section{Insert Table 5}

\section{Insert Table 6}

\section{Conclusions}

Using a stochastic cost frontier model we explored the cost-efficiency differences across various hospital types. Consistent with the previous studies, the 
results point to considerable unexploited scale economies in a majority of the studied hospitals. The results also suggest that hospitals with a wider range of specializations are relatively more costly than those specializing in fewer categories of medical services. However, the cost differences resulting from specialization are limited to a few percentage points for a relatively large change in the number of services.

The richer data compared to the previous studies on Swiss hospitals were used to identify the effect of teaching activities on hospital costs through the number of internships and measures of teaching accreditation. The results suggest that the considerable excess costs of university hospitals, reported in previous studies, can be explained by more extensive teaching activities in those hospitals as well as the relative complexity of the offered medical care as assessed for training purposes. However, our analysis indicates that even after controlling for such differences university hospitals have shown a relatively poor cost-efficiency in the first two or three years of the sample period. The results also point to a statistically significant improvement of efficiency of university hospitals over the sample period.

Finally, the statistical tests do not provide any evidence of statistically significant efficiency differences across ownership and subsidization categories. This result has been confirmed by a panel data model that integrates the ownership/subsidy indicators. However, lack of evidence for significant efficiency advantage of one type over another might be restricted to the available data, thus should be considered with caution. In fact, the potential correlation between hospital types and other cost driving factors might mask the actual ownership/subsidy effects.

The present analysis has two main shortcomings that call for further study. First, the available data do not allow for a sufficient account of differences regarding the quality of care and case-mix severity. Although the adopted econometric 
specification accounts for unobserved hospital-specific heterogeneity through individual random effects, the potential correlation of omitted variables with hospital types is neglected. Secondly, the cost frontier model while having a practical convenience in comparing the individual hospitals with the "best" observed practice, prove to be sensitive to the model specification.

\section{Acknowledgements}

The authors are grateful to the Swiss Federal Statistical Office for providing the data and their financial support. They also wish to thank this journal's editor and two anonymous referees for their helpful suggestions and André Meister, Luca Stäger and Luca Crivelli for their help in understanding the data. Part of this research has been financed by the Swiss National Science Foundation through research grant 100012-108288, which is gratefully acknowledged. The views expressed in this paper are those of the authors and do not necessarily reflect the position of any institution.

\section{Appendix}

\section{Insert Table A.1}

\section{References}

Aigner D, Lovell CAK, Schmidt P. 1977. Formulation and Estimation of Stochastic Frontier Production Function Models. J Econom 6: 21-37.

Aletras VH. 1999. A comparison of hospital scale effects in short-run and long-run cost functions. Health Econ 8: 521-530.

APDRG Suisse. 2003. Cost Weights version 4.1. Institut de Santé et d'Economie Prilly, Switzerland, available at: www.apdrgsuisse.ch.

Battese GE, Coelli T. 1992. Frontier Production Functions, Technical Efficiency and Panel Data: With Application to Paddy Farmers in India. Journal of Productivity Analysis 3: 153-169.

Bös D. 1986. Public Enterprise Economics. North-Holland: Amsterdam. 
Breyer F. 1987. The specification of a hospital cost function: A comment on the recent literature. J Health Econ 6: 147-157.

Brown HS. 2003. Managed care and technical efficiency. Health Econ 12 (2): 149158.

Bruning ER, Register CA. 1989. Technical efficiency within hospitals: do profit incentives matter? Appl Econ 21: 1217-1233.

Carey K. 1997. A panel data design for estimation of hospital cost functions. Rev Econ Stat 79 (2): 443-453.

Cornes R. 1992. Duality and Modern Economics. Cambridge University Press: Cambridge.

Cornwell Ch, Schmidt P, Sickles RC. 1990. Production frontiers with cross-sectional and time-series variation in efficiency levels. J Econom 46: 185-200.

Crivelli L, Filippini M, Lunati D. 2001. Dimensione ottima degli ospedali in uno Stato federale. (in Italian) Econ Pubblica 5: 97-119.

Dranove D. 1998. Economies of scale in non-revenue producing cost centers: implications for hospital mergers. J Health Econ 17: 69-83.

Eakin BK. 1991. Allocative inefficiency in the production of hospital services. South Econ $J 58$ (1): 240-248.

Farsi M, Filippini M, Greene W. 2005. Efficiency Measurement in Network Industries: Application to the Swiss Railway Companies. Journal of Regulatory Economics 28 (1): 65-86.

Farsi M, Filippini M, Kuenzle M. 2005. Unobserved Heterogeneity in Stochastic Cost Frontier Models: An Application to Swiss Nursing Homes. Appl Econ 37: 21272141.

Farsi M, Filippini M. 2004. An Empirical Analysis of Cost Efficiency in Non-profit and Public Nursing Homes. Annals of Public and Cooperative Economics 75 (3): 339-365.

Farsi M, Filippini M. 2006. An analysis of efficiency and productivity in Swiss hospitals. Schweiz Z Volkswirtsch Stat 142 (1): 1-37.

Folland ST, Hofler RA. 2001. How reliable are hospital efficiency estimates? Exploiting the dual to homothetic production. Health Econ 10: 683-698.

Gouriéroux Ch, Monfort A. 1996. Simulation-Based Econometric Methods. Oxford University Press: Oxford.

Greene W. 2003. Simulated Likelihood Estimation of the Normal-Gamma Stochastic Frontier Function. Journal of Productivity Analysis 19 (2/3): 179-190.

Greene W. 2004. Distinguishing between heterogeneity and inefficiency: Stochastic frontier analysis of the World Health Organization's panel data on national health care systems. Health Econ 13: 959-980

Greene W. 2005. Reconsidering Heterogeneity in Panel Data Estimators of the Stochastic Frontier Model. J Econom 126 (2): 269-303. 
Griffin RC, Montgomery JM, Rister ME. 1987. Selecting Functional Form in Production Function Analysis. Western Journal of Agricultural Economics 12 (2): 216-227.

Hadley J, Zuckerman S. 1994. The role of efficiency measurement in hospital rate setting. J Health Econ 13: 335-340.

Heshmati A. 2002. Productivity measurement in Swedish departments of gynecology and obstetrics. Structural Change and Dynamics 13: 315-336.

Horrace WC, Schmidt P 1996. Confidence Statements for Efficiency Estimates from Stochastic Frontier Models. Journal of Productivity Analysis 7: 257-82.

Jacobs R, Dawson D. 2003. Hospital efficiency targets. Health Econ 12 (8): 669-684.

Jensen U 2000. Is it Efficient to Analyse Efficiency Rankings? Empir Econ 25: 189208.

Jondrow J, Materov I, Lovell K, Schmidt P. 1982. On the estimation of technical inefficiency in the stochastic frontier production function model. $J$ Econom 19 (2/3): 233-238.

Kruskal WH, Wallis WA. 1952. Use of ranks in one-criterion variance analysis. J Am Stat Assoc 47: 583-621.

Kumbhakar SC, Hjalmarsson L. 1995. Estimation of technical inefficiency in panel data models with firm- and time-specific effects. Journal of Applied Econometrics 10: 33-47.

Kumbhakar SC, Lovell CAK. 2000. Stochastic Frontier Analysis. Cambridge University Press: Cambridge.

Kumbhakar SC. 1991. Estimation of technical inefficiency in panel data models with firm- and time-specific effects. Econ Lett 36: 43-48.

Li T, Rosenman R. 2001. Estimating hospital costs with a generalized Leontief function. Health Econ 10: 523-538.

Linna M. 1998. Measuring hospital cost efficiency with panel data models. Health Econ 7: 415-427.

Newhouse JP. 1994. Frontier Estimation: How Useful a Tool for Health Economics. $J$ Health Econ 13: 317-322.

Pitt M, Lee L. 1981. The measurement and sources of technical inefficiency in Indonesian weaving industry. J Dev Econ 9: 43-64.

Polachek S, Yoon B. 1996. Panel estimates of a two-tiered earnings frontier. Journal of Applied Econometrics 11: 169-178.

Rosko MD. 2001. Cost efficiency of US hospitals: A stochastic frontier approach. Health Econ 10: 539-551.

Schmidt P, Sickles RC. 1984. Production Frontiers and Panel Data. Journal of Business and Economic Statistics 2: 367-374.

Scuffham PA, Devlin NJ, Jaforullah M. 1996. The structure of costs and production in New Zealand public hospitals: an application of the transcendental logarithmic variable cost function. Appl Econ 28: 75-85. 
SFSO. 1997a. Statistiques des établissements de santé (soins intra-muros), Statistique des hôpitaux, Conception détaillée, Déc. 1997. (in French) Swiss Federal Statistical Office, Neuchâtel, Switzerland, www.statistik.admin.ch.

SFSO. 1997b. Statistiques des établissements de santé (soins intra-muros), Statistique médicale des hôpitaux, Conception détaillée 1997. (in French) Swiss Federal Statistical Office, Neuchâtel, Switzerland, www.statistik.admin.ch.

SFSO. 2001. Statistiques des établissements de santé (soins intra-muros), Typologie des hôpitaux. (in French) Swiss Federal Statistical Office, Neuchâtel, Switzerland, www.statistik.admin.ch.

Sickles RC. 2005. Panel estimators and the identification of firm-specific efficiency levels in parametric, semiparametric and nonparametric settings. J Econom 126 (2): 305-334.

Singh S, Coelli T. 2001. Performance of dairy plants in the cooperative and private sectors in India. Annals of Public and Cooperative Economics 72 (4): 453-479.

Skinner J 1994. What do stochastic frontier cost functions tell us about inefficiency? $J$ Health Econ 13: 323-328.

Steinmann L, Dittrich G, Karmann A, Zweifel P. 2004. Measuring and comparing the (in)efficiency of German and Swiss hospitals. Eur J Health Econ 5: 216-226.

Steinmann L, Zweifel P. 2003. On the (in)efficiency of Swiss hospitals. Appl Econ 35: 361-370.

Street A 2003. How Much Confidence Should We Place in Efficiency Estimates? Health Econ 12: 895-907.

Vita MG. 1990. Exploring hospital production relationships with flexible functional forms. J Health Econ 9: 1-21.

Vitaliano D, Toren M. 1996. Hospital cost and efficiency in a regime of stringent regulation. East Econ J 22:161-184.

Wagstaff A, Lopez G. 1995. Hospital costs in Catalonia: a stochastic frontier analysis. Appl Econ Lett 3: 471-474.

Wagstaff A. 1989. Estimating Efficiency in the Hospital Sector: a Comparison of Three Statistical Cost Frontier Models. Appl Econ 21: 659-672.

Zuckerman S, Hadley J, Iezzoni L. 1994. Measuring hospital efficiency with frontier cost functions. J Health Econ 13: 255-280. 
Figure 1: Efficiency trend in university hospitals

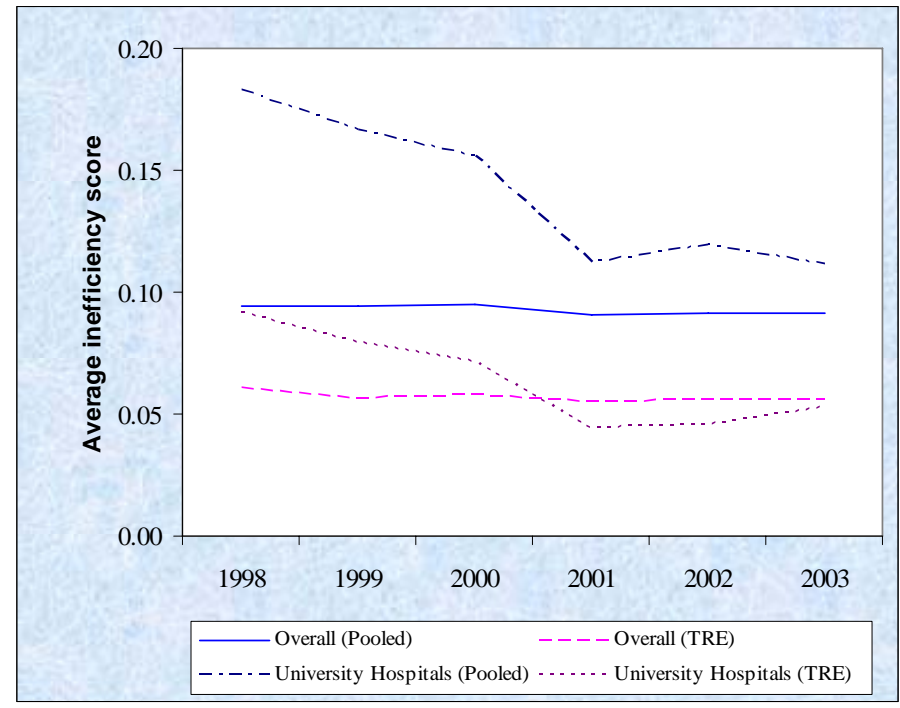

Figure 2: Average AP-DRG cost weight

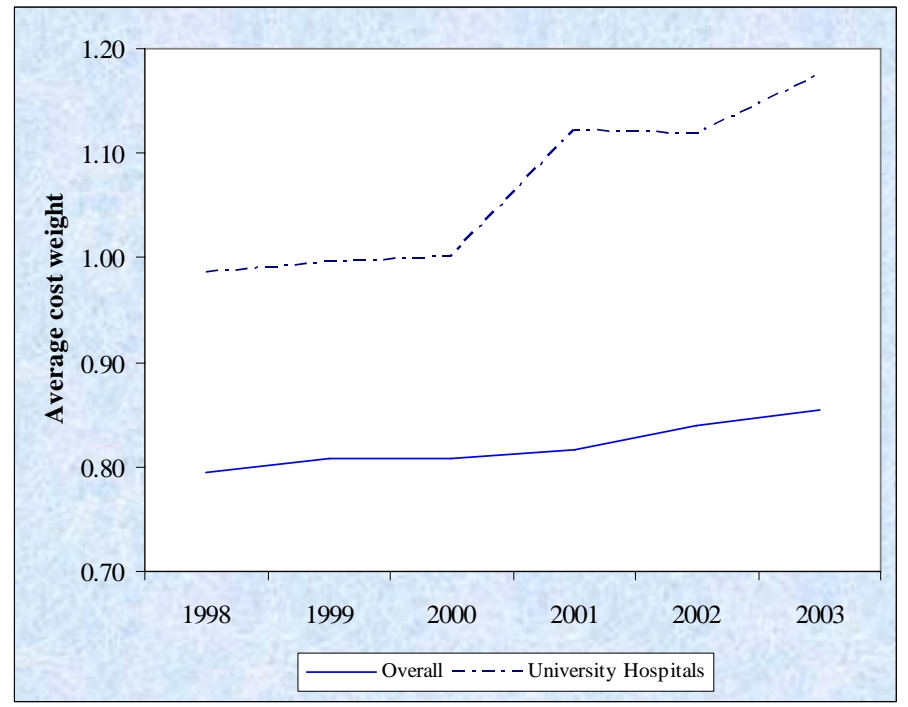


Table 1: Descriptive statistics

\begin{tabular}{|c|c|c|c|c|c|c|}
\hline Continuous variables & Mean & Std. Dev. & Min. & Max. & Dummy variables & Mean \\
\hline $\begin{array}{l}\text { Hospital's total costs } \\
\text { (CHF '000) }\end{array}$ & 86'697 & $139 ' 667$ & $5^{\prime} 036$ & $884^{\prime} 764$ & Emergency Room & 0.9165 \\
\hline Number of hospitalizations & 7'542 & 7'814 & 367 & $50 ' 774$ & Geriatrics & 0.5217 \\
\hline $\begin{array}{l}\text { Number of hospitalizations } \\
\text { (AP-DRG adjusted) }\end{array}$ & $6 ' 555$ & 7'825 & 208 & $49 ' 251$ & Year 1998 & 0.1108 \\
\hline $\begin{array}{c}\text { Average total cost per } \\
\text { hospitalization (CHF '000) }\end{array}$ & 10.17 & 4.53 & 4.39 & 53.78 & Year 1999 & 0.1573 \\
\hline $\begin{array}{l}\text { Average AP-DRG } \\
\text { cost weight }\end{array}$ & 0.8224 & 0.1127 & 0.5204 & 1.4735 & Year 2000 & 0.1846 \\
\hline Number of patient-days & $63 ' 148$ & 63'309 & 4'997 & $410 ' 140$ & Year 2001 & 0.1878 \\
\hline $\begin{array}{c}\text { Average length of hospitalizations } \\
\text { (days) }\end{array}$ & 10.0 & 5.0 & 3.9 & 49.1 & Year 2002 & 0.1878 \\
\hline $\begin{array}{c}\text { Average length of full } \\
\text { hospitalizations (days) }^{\mathrm{a}}\end{array}$ & 11.0 & 4.9 & 4.5 & 49.1 & Year 2003 & 0.1717 \\
\hline $\begin{array}{l}\text { Hospiatl's outpatient revenues } \\
\text { (CHF '000) }\end{array}$ & $12 ' 944$ & $21 ' 827$ & 24 & 144'802 & $\begin{array}{c}\text { Private for-profit } \\
\text { Hospital }\end{array}$ & 0.0979 \\
\hline $\begin{array}{l}\text { Hospital capacity } \\
\text { (number of beds) }\end{array}$ & 213.2 & 220.2 & 20 & 1277 & $\begin{array}{c}\text { Private non-profit } \\
\text { hospital }\end{array}$ & 0.3355 \\
\hline $\begin{array}{l}P_{K}(\text { capital price }) \\
\text { CHF '000 per bed }\end{array}$ & 24.86 & 23.71 & 3.08 & 242.57 & Public hospital & 0.5666 \\
\hline $\begin{array}{c}P_{L}-\text { physicians }^{\mathrm{b}} \\
(\text { CHF per day) }\end{array}$ & 345.17 & 133.43 & 93.22 & 1'044.49 & Subsidized hospital & 0.9085 \\
\hline $\begin{array}{c}P_{L}-\text { other employees }^{c} \\
(C H F \text { per day })\end{array}$ & 177.48 & 32.73 & 76.82 & 320.02 & University hospital & 0.0385 \\
\hline Nurse per bed ratio & 1.363 & 0.506 & 0.474 & 4.410 & & \\
\hline $\begin{array}{l}\text { Number of hospital's medical } \\
\text { service centers }\end{array}$ & 31.7 & 17.0 & 4 & 81 & & \\
\hline $\begin{array}{c}\text { Number of hospital's } \\
\text { non-medical units }{ }^{d}\end{array}$ & 31.7 & 7.3 & 9 & 48 & & \\
\hline $\begin{array}{c}\text { Number of postgraduate medical } \\
\text { training position }\end{array}$ & 45.6 & 95.4 & 1 & 583 & & \\
\hline $\begin{array}{l}\text { Fraction of ambulatory clinics in } \\
\text { medical units }\end{array}$ & 0.1216 & 0.0822 & 0 & 0.4286 & & \\
\hline $\begin{array}{l}\text { Fraction of medical units } \\
\text { recognized by FMH }\end{array}$ & 0.2334 & 0.1904 & 0 & 0.8571 & & \\
\hline $\begin{array}{l}\text { Fraction of accredited training } \\
\text { positions (FMH types A and B) }\end{array}$ & 0.6109 & 0.3553 & 0 & 1 & & \\
\hline
\end{tabular}

- The sample includes 623 observations from 148 general hospitals (1998-2003).

- All monetary values are adjusted by the global consumer price index relative to 2003 prices.

- Semi-hospitalizations (shorter than 24 hours) are considered as one-day hospitalizations.

${ }^{a}$ Excludes semi-hospitalizations (over-night hospital stays shorter than 24 hours).

b Employed physicians' average salary, adjusted for social benefits and excludes fees.

${ }^{c}$ Average salary (adjusted for social benefits) of all hospital employees except physicians.

${ }^{\mathrm{d}}$ Includes medicotechnical, therapeutic and infrastructure units. 
Table 2: Number of hospitals and average size by ownership/subsidy (1998-2003)

\begin{tabular}{|c|c|c|c|c|c|}
\hline & & PUBLIC & $\begin{array}{c}\text { PRIVATE } \\
\text { NON-PROFIT }\end{array}$ & $\begin{array}{c}\text { PRIVATE FOR } \\
\text { PROFIT }\end{array}$ & TOTAL \\
\hline \hline \multirow{2}{*}{ SUBSIDIZED } & Hospitals & 353 & 175 & 38 & 566 \\
& Hospital size (beds) & 262 & 155 & 194 & 224 \\
\hline \multirow{2}{*}{ NON SUBSIDIZED } & Hospitals & - & 34 & 23 & 57 \\
& Hospital size (beds) & & 80 & 133 & 101 \\
\hline \multirow{2}{*}{ TOTAL } & Hospitals & 353 & 209 & 61 & 623 \\
& Hospital size (beds) & 262 & 143 & 171 & 213 \\
\hline
\end{tabular}


Table 3: Estimation results

\begin{tabular}{|c|c|c|}
\hline & Pooled Model & True RE Model \\
\hline \multirow{2}{*}{$\begin{array}{l}\text { Number of hospitalizations } \\
\text { (AP-DRG adjusted) }\end{array}$} & $0.6914^{*}$ & $0.6315^{*}$ \\
\hline & $(0.0152)$ & $(0.0069)$ \\
\hline \multirow{2}{*}{$\begin{array}{c}\text { Average length of } \\
\text { hospitalizations }\end{array}$} & $0.5100^{*}$ & $0.4023^{*}$ \\
\hline & $(0.0194)$ & $(0.0088)$ \\
\hline \multirow{2}{*}{ Outpatient revenues } & $0.1498 *$ & $0.1456^{*}$ \\
\hline & $(0.0093)$ & $(0.0037)$ \\
\hline \multirow{2}{*}{$P_{K}$ (capital price) } & $0.1211^{*}$ & $0.1225^{*}$ \\
\hline & $(0.0096)$ & $(0.0045)$ \\
\hline \multirow{2}{*}{$P_{L}-$ physicians } & $0.0744^{*}$ & $0.0311^{*}$ \\
\hline & $(0.0179)$ & $(0.0085)$ \\
\hline \multirow{2}{*}{$P_{L}$ - others } & $0.2333 *$ & $0.1533^{*}$ \\
\hline & $(0.0406)$ & $(0.0183)$ \\
\hline \multirow{2}{*}{ Nurse per bed } & $0.2406^{*}$ & $0.1423^{*}$ \\
\hline & $(0.0262)$ & $(0.0118)$ \\
\hline \multirow{2}{*}{$\begin{array}{l}\text { Number of } \\
\text { medical units }\end{array}$} & $0.0380 *$ & $0.0573 *$ \\
\hline & $(0.0149)$ & $(0.0070)$ \\
\hline \multirow{2}{*}{$\begin{array}{c}\text { Number of } \\
\text { non-medical units }\end{array}$} & -0.0321 & $0.0743^{*}$ \\
\hline & $(0.0358)$ & $(0.0179)$ \\
\hline \multirow{2}{*}{$\begin{array}{c}\text { Number of } \\
\text { training positions }\end{array}$} & $0.1003^{*}$ & $0.0882 *$ \\
\hline & $(0.0108)$ & $(0.0049)$ \\
\hline \multirow{2}{*}{$\begin{array}{c}\text { Fraction of } \\
\text { ambulatory clinics }\end{array}$} & $-0.1747^{*}$ & $-0.3037^{*}$ \\
\hline & $(0.0705)$ & $(0.0329)$ \\
\hline \multirow{2}{*}{$\begin{array}{l}\text { Fraction of medical units } \\
\text { recognized by FMH }\end{array}$} & 0.0150 & $0.0476^{*}$ \\
\hline & $(0.0369)$ & $(0.0184)$ \\
\hline \multirow{2}{*}{$\begin{array}{c}\text { Fraction of training } \\
\text { positions } A \text { and } B\end{array}$} & $0.0471^{*}$ & 0.0191 \\
\hline & $(0.0237)$ & $(0.0110)$ \\
\hline \multirow{2}{*}{ Emergency Room } & $-0.0727^{*}$ & $0.0279 *$ \\
\hline & $(0.0224)$ & $(0.0114)$ \\
\hline \multirow{2}{*}{ Geriatrics } & $-0.0345^{*}$ & $-0.0281^{*}$ \\
\hline & $(0.0126)$ & $(0.0057)$ \\
\hline \multirow{2}{*}{ Year 1999} & -0.0168 & -0.008 \\
\hline & $(0.0204)$ & $(0.0112)$ \\
\hline \multirow{2}{*}{ Year 2000} & 0.0111 & 0.0128 \\
\hline & $(0.0204)$ & $(0.0096)$ \\
\hline \multirow{2}{*}{ Year 2001} & 0.0313 & $0.0402 *$ \\
\hline & $(0.0200)$ & $(0.0100)$ \\
\hline \multirow{2}{*}{ Year 2002} & $0.0525 *$ & $0.0604^{*}$ \\
\hline & $(0.0202)$ & $(0.0097)$ \\
\hline \multirow{2}{*}{ Year 2003} & $0.0511 *$ & $0.0618^{*}$ \\
\hline & $(0.0207)$ & $(0.0099)$ \\
\hline \multirow{2}{*}{ Constant $(\alpha)$} & 0.2081 & $1.2165^{*}$ \\
\hline & $(0.2418)$ & $(0.1097)$ \\
\hline \multirow{2}{*}{$\sigma_{\alpha}$} & \multirow{2}{*}{-} & $0.1378^{*}$ \\
\hline & & $(0.0031)$ \\
\hline$\sigma$ & $0.1592 *$ & $0.0872 *$ \\
\hline [where: $\sigma^{2}=\sigma_{u}{ }^{2}+\sigma_{v}{ }^{2}$ ] & $(0.0002)$ & $(0.0036)$ \\
\hline$\lambda=\sigma / \sigma$ & $1.0698 *$ & $1.5521^{*}$ \\
\hline$\lambda=\sigma_{u} / \sigma_{v}$ & $(0.1094)$ & $(0.2124)$ \\
\hline Log Likelihood & 391.59 & 610.19 \\
\hline
\end{tabular}

* Significant at 5\%; Standard errors are given in parentheses; Dependent variable is hospital's total costs in logs; All variables except dummies and the three fractions are in logarithms. 
Table 4: Descriptive summary of inefficiency estimates

\begin{tabular}{cccccccc}
\hline Model & Mean & Std. Dev. & Min. & $\begin{array}{c}\text { 1st } \\
\text { Quartile }\end{array}$ & Median & $\begin{array}{c}\text { 3rd } \\
\text { Quartile }\end{array}$ & Max. \\
\hline \hline Pooled & 0.0926 & 0.0401 & 0.0299 & 0.0656 & 0.0859 & 0.1084 & 0.3249 \\
\hline True RE & 0.0568 & 0.0291 & 0.0114 & 0.0387 & 0.0502 & 0.0673 & 0.2622 \\
\hline
\end{tabular}

Table 5: Average inefficiency by ownership/subsidy type (pooled model)

\begin{tabular}{|c|c|c|c|c|}
\hline & PUBLIC & $\begin{array}{c}\text { PRIVATE } \\
\text { NON-PROFIT }\end{array}$ & $\begin{array}{c}\text { PRIVATE } \\
\text { FOR-PROFIT }\end{array}$ & TOTAL \\
\hline \hline SUBSIDIZED & 0.0896 & 0.0941 & 0.0983 & 0.0916 \\
\hline NON SUBSIDIZED & - & 0.1099 & 0.0906 & 0.1021 \\
\hline TOTAL & 0.0896 & 0.0967 & 0.0954 & 0.0926 \\
\hline
\end{tabular}

Table 6: Average inefficiency by ownership/subsidy type (TRE model)

\begin{tabular}{|c|c|c|c|c|}
\hline & PUBLIC & $\begin{array}{c}\text { PRIVATE } \\
\text { NON-PROFIT }\end{array}$ & $\begin{array}{c}\text { PRIVATE } \\
\text { FOR-PROFIT }\end{array}$ & TOTAL \\
\hline \hline SUBSIDIZED & 0.0551 & 0.0586 & 0.0594 & 0.0565 \\
\hline NON SUBSIDIZED & & 0.0591 & 0.0605 & 0.0597 \\
\hline TOTAL & 0.0551 & 0.0587 & 0.0598 & 0.0568 \\
\hline
\end{tabular}


Table A.1: Total cost function with a GLS model with random effects

\begin{tabular}{|c|c|c|}
\hline & Model I & Model II \\
\hline Private For-Profit & - & $\begin{array}{r}0.0125 \\
(0.0163) \\
\end{array}$ \\
\hline Private Non-Profit & - & $\begin{array}{r}0.0154 \\
(0.0172) \\
\end{array}$ \\
\hline Subsidized & - & $\begin{array}{r}0.0488 \\
(0.0373) \\
\end{array}$ \\
\hline $\begin{array}{l}\text { Number of hospitalizations } \\
\text { (AP-DRG adjusted) }\end{array}$ & $\begin{array}{l}0.6238 * \\
(0.0168)\end{array}$ & $\begin{array}{l}0.6227^{*} \\
(0.0169)\end{array}$ \\
\hline $\begin{array}{c}\text { Average length of } \\
\text { hospitalizations }\end{array}$ & $\begin{array}{l}0.3914 * \\
(0.0195) \\
\end{array}$ & $\begin{array}{l}0.3926 * \\
(0.0197) \\
\end{array}$ \\
\hline Outpatient revenues & $\begin{array}{l}0.1467 * \\
(0.0098) \\
\end{array}$ & $\begin{array}{l}0.1485^{*} \\
(0.0100) \\
\end{array}$ \\
\hline$P_{K}($ capital price $)$ & $\begin{array}{l}0.1202 * \\
(0.0091) \\
\end{array}$ & $\begin{array}{l}0.1216^{*} \\
(0.0094) \\
\end{array}$ \\
\hline$P_{L}$ - physicians & $\begin{array}{l}0.0300 * \\
(0.0127) \\
\end{array}$ & $\begin{array}{l}0.0292 * \\
(0.0128) \\
\end{array}$ \\
\hline$P_{L}$ - others & $\begin{array}{l}0.1719 * \\
(0.0299) \\
\end{array}$ & $\begin{array}{l}0.1719 * \\
(0.0299) \\
\end{array}$ \\
\hline Nurse per bed & $\begin{array}{l}0.1472 * \\
(0.0197) \\
\end{array}$ & $\begin{array}{l}0.1459 * \\
(0.0197) \\
\end{array}$ \\
\hline $\begin{array}{l}\text { Number of } \\
\text { medical units }\end{array}$ & $\begin{array}{l}0.0600^{*} \\
(0.0159) \\
\end{array}$ & $\begin{array}{l}0.0615^{*} \\
(0.0161) \\
\end{array}$ \\
\hline $\begin{array}{c}\text { Number of } \\
\text { non-medical units }\end{array}$ & $\begin{array}{l}0.0839 * \\
(0.0362) \\
\end{array}$ & $\begin{array}{l}0.0790^{*} \\
(0.0364) \\
\end{array}$ \\
\hline $\begin{array}{l}\text { Number of } \\
\text { training positions }\end{array}$ & $\begin{array}{l}0.0826^{*} \\
(0.0102) \\
\end{array}$ & $\begin{array}{l}0.0818 * \\
(0.0103) \\
\end{array}$ \\
\hline $\begin{array}{c}\text { Fraction of } \\
\text { ambulatory clinics }\end{array}$ & $\begin{array}{l}-0.2867 * \\
(0.0700) \\
\end{array}$ & $\begin{array}{l}-0.2933^{*} \\
(0.0703) \\
\end{array}$ \\
\hline $\begin{array}{l}\text { Fraction of medical units } \\
\text { recognized by FMH }\end{array}$ & $\begin{array}{c}0.0481 \\
(0.0294) \\
\end{array}$ & $\begin{array}{r}0.0450 \\
(0.0295) \\
\end{array}$ \\
\hline $\begin{array}{c}\text { Fraction of training } \\
\text { positions } A \text { and B }\end{array}$ & $\begin{array}{c}0.0162 \\
(0.0158) \\
\end{array}$ & $\begin{array}{r}0.0133 \\
(0.0160) \\
\end{array}$ \\
\hline Emergency Room & $\begin{array}{c}0.0260 \\
(0.0255) \\
\end{array}$ & $\begin{array}{r}0.0228 \\
(0.0260) \\
\end{array}$ \\
\hline Geriatrics & $\begin{array}{l}-0.0305^{*} \\
(0.0122) \\
\end{array}$ & $\begin{array}{l}-0.0313^{*} \\
(0.0123)\end{array}$ \\
\hline Year 1999 & $\begin{array}{l}-0.0121 \\
(0.0086)\end{array}$ & $\begin{array}{l}-0.0118 \\
(0.0086)\end{array}$ \\
\hline Year 2000 & $\begin{array}{c}0.0100 \\
(0.0091) \\
\end{array}$ & $\begin{array}{c}0.0097 \\
(0.0091) \\
\end{array}$ \\
\hline Year 2001 & $\begin{array}{l}0.0356^{*} \\
(0.0087) \\
\end{array}$ & $\begin{array}{l}0.0359 * \\
(0.0087) \\
\end{array}$ \\
\hline Year 2002 & $\begin{array}{l}0.0566 * \\
(0.0091) \\
\end{array}$ & $\begin{array}{l}0.0556 * \\
(0.0092) \\
\end{array}$ \\
\hline Year 2003 & $\begin{array}{l}0.0581 * \\
(0.0097)\end{array}$ & $\begin{array}{l}0.0572 * \\
(0.0098) \\
\end{array}$ \\
\hline Constant & $\begin{array}{l}1.2490 * \\
(0.2103)\end{array}$ & $\begin{array}{l}1.2115^{*} \\
(0.2116) \\
\end{array}$ \\
\hline
\end{tabular}

* Significant at 5\% or less; Standard errors are given in parentheses; Dependent variable is hospital's total costs; All variables except fractions and dummies are in logarithms. 